\title{
Geographies of sports development: the role of space and place
}

\author{
Emma Wainwright \\ Nicola Ansell
}

\section{Introduction}

Sports geography or the geography of sports is often regarded as the study of spatial variations in the pursuit of various sports and the impact that sporting activities have on the landscape (Johnston, 2000a). John Bale (2003, p. 2), the most prolific writer on sports geography, has chastised geographers for neglecting the study of sport arguing, "sport - like geography - is a spatial science" and warrants much greater interest and further research (see also Bale and Vertinsky, 2004). However, sports geography remains quite narrowly conceived with an especially strong focus on changing patterns of sporting activities (Johnston, 2000a).

However, thinking about the geography or the multiple geographies of sports development can counter some of these shortfalls, and broaden our understanding of both sports development and sports geography. Essentially, sports development is an encounter between people and place that takes place in and through space. In its pitch to host the 2014 Commonwealth Games, Glasgow has titled its bid document 'People, Place, Passion', emphasising the centrality of this encounter and the fundamental role

of geography. As Louise Martin, Chair of the Commonwealth Games Council for Scotland explained, "the title reflects the context for the Games - a diverse and welcoming population, an amazing city and country and an extraordinary passion for sport and the Games" (http://www.cgcs.org.uk/News accessed 8/10/07).

Space and the spatial are understood by geographers in a number of different ways. Spaces of sports development may be absolute, material and concrete but can also be metaphorical and imaginative. Thus sports development is used to shape space and give meaning to place. This latter interpretation of space and the spatial differs markedly from a more empiricist view of space as enabling sports development to be situated and marked out, with patterns of location waiting to be recognised and mapped. Through this chapter we reinforce the notion of sports development as a 
process that takes place through space involving negotiations over the meaning of place and who belongs in it.

As stipulated in the introductory chapter, the discourse of modern development has emphasised temporal change through notions of enlightenment and progress. Moreover, this temporality has been prioritised over any sense of the spatial and spatial change. As geographers have argued pervasively, social science has privileged time over space, constructing them as binary opposites, with time seen as a source of change, movement and history, and space marginalised and viewed as static. However, Massey (2005) among others has argued that, on the contrary, space is inherently dynamic. This conceptualisation is essential in thinking through sports development, not just as a temporal process but as a thoroughly spatial one as well. It is this spatial dimension that is too often lacking and hinders a fuller understanding of sports development.

This chapter begins by outlining what geographers mean by the terms space and place and how they are used here. It then goes on to place sports development within a wider discourse of urban development and regeneration. Intended to ameliorate the negative consequences of urban decline, regeneration programmes are increasingly using some form of sports development to rejuvenate and support vulnerable communities and localities, and to create uniqueness and identity. By exploring a number of examples, the processes and outcomes of regeneration through sports development will be probed. In so doing, the chapter will highlight the power struggles over the meaning of place and inclusion that these processes can create for insiders (people who live there) and outsiders (people who visit). In particular it will stress the differential involvement and impact sports development can have in different areas and upon different groups. Further, the chapter will explore the role of sports development in place-(re)making in both a material context (through structural and environmental change) and an imaginary sense (of place marketing and promotion).

Throughout, a number of examples and case studies are used which work through different scales and articulate a range of activity spaces, from the local impacts of stadia to the hosting of a global sporting event. As large-scale sporting developments 
bring into sharp focus local and global geographies of sports development and their tensions, the chapter's main case study, referred to throughout, is that of the 1992 Barcelona Olympic Games and its legacy. By probing sports development through a spatial dimension, the chapter stresses the complex considerations that need to be addressed by sports development managers in relation to different groups and at different spatial scales. Sports development is a means by which socio-spatial relations are produced, maintained and resisted.

\section{The importance of space and place}

Space and place are central themes in geographical thinking. Despite this, they remain difficult to define and have been used in differing ways and through varied perspectives through the history of Geography as a discipline. However, before articulating their relevance and purchase on sports development, these terms need to be explored and explained.

Space is often considered the 'fundamental' of human geography (Thrift, 2003) and the production of geographical knowledge is anchored in claims to know space in particular ways. Historically, notions of space have focused on 'locating' events, places and phenomena on the earth's surface and representing these in maps (Gregory, 2000). Philosophical debates about space have been dominated by the dichotomy of absolute space and relational space. The former sees space as a container: clearly distinct, real and objective (Mayhew and Penny, 1992). Hence absolute space focuses on the characteristics of things in terms of their concentration and dispersion and it is this notion of the spatial that is closely linked to the processes and history of mapmaking and the concern for precise measurement of locational relationships (Goodall, 1987). In contrast, relative or relational space is perceptual and socially produced and focuses on the characteristics of places (Goodall, 1987).

Using these notions of space, some geographers consider the production of material, concrete spaces, while others are concerned with the production of imagined and symbolic spaces. Importantly, geographers emphasise the recursive relationship between the two: space is continually created and constructed through social relations

just as social relations are constructed through and by space. Thus space is dynamic it is always in the process of being made and given meaning. In this chapter, then, it is 
this notion of relational space that we use to explore the construction and contestation of material, social and imagined spaces of sports development.

Place is a commonly used term in the everyday vernacular but its meaning can become obscured. Agnew (1987) has argued that place consists of three elements: location - a point in space with specific relations to other points in space; locale - the broader context (both built and social) for social relations; and, sense of place subjective feelings associated with place. Until recently, these three perspectives were framed by a 'mosaic' metaphor that implied places were singular, discrete and unique (Castree, 2003). However, an increasingly globalised world has challenged geographers to think differently about these understandings of place:

"The globalisation of production, trade, finance, politics and culture, themselves facilitated by remarkable advances in transport and telecommunications, has made the world a 'global village". (Castree, 2003, p. 166)

Thus, for some writers, globalisation has signalled the end of place (see Castells, 1996). However, rather than making the notion of place invalid, most geographers argue that globalisation requires a redefinition of what place means. Places in the contemporary world are clearly no longer separate but connected by an intricate web of flows and processes that stretch across the globe. Thus we need to have a "global sense of the local" (Massey, 1994, p. 51), with global forces having variable local effects and globalisation coincident with new forms of place differentiation.

The importance of globalising forces in understanding and challenging notions of place and identifying places underlines the significance of scale. Scale refers to one or more levels of representation, experience and organisation of geographical events and processes (Johnston, 2000b). In this chapter in discussing the role of space and place, we will explore how sports developments are shaped by both local and global forces and produce local and global outcomes. The local and global are intricately caught up with one another, causing geographers to discuss the 'glocalisation' (Swyngedouw, 1989) of place and identity.

\section{Sports development and urban regeneration}


Many major cities in Europe and North America developed through the rise of industrial capital from the mid-nineteenth century onwards. However, this process of industrial development began to subside in the closing decades of the twentieth century with many cities as a consequence experiencing severe economic and social problems. Places that were once economically and socially 'active' were being transformed into 'places of loss', characterised by an abandoned industrial landscape (Degen, 2001). To mitigate the effects of this deindustrialisation and ameliorate the negative consequences of urban decline, regeneration initiatives have been pursued (Hall, 2006) by both public and private interests. Though these initiatives vary widely, they all share one or more of the following goals: improvements to the physical environment, improvements to the quality of life of certain populations, improvements to the social welfare of certain populations, and the enhancement of the economic prospects of certain populations (Hall, 2006). As Hall argues, regeneration projects have changed over time from a concern primarily with living conditions to include social, economic and environmental goals. The latter having become especially important as environmental sustainability has risen up the political agenda since the 1992 UN Earth Summit in Rio de Janeiro and the international adoption of Agenda 21. Significantly, the International Olympic Committee was the first international sports governing body to implement the Rio recommendations and developed its own 'Agenda 21' policies which since have been used as a blueprint in sports development policies of many international and national sports governing bodies (IOC, 1992).

Increasingly, sporting developments of varying size and scope are being used to spearhead regeneration through the use of public-private partnerships. Events like the Olympics and World Cup are the oft-cited 'mega-events' linked to regeneration processes and outcomes, rated mainly for their post-event 'legacy' (as discussed in chapter 7). But, on a smaller scale, sports stadia have grown in importance as a tool of urban regeneration. This has been a notable trend in the UK in recent years where a number of cities have developed policy founded on the ability of sporting events and stadia to stimulate economic and physical regeneration (see Gratton and Henry, 2001 for a good review). By focusing on a number of different events and developments, we reflect here on the geographical impact they can have on urban spaces and local residents. 
In terms of prestige, international media exposure and potential for regenerating an area, the 'mega-event' of the Olympics is the most highly sought after (Hall, 2006). The 1992 Barcelona Games are often held up as the ultimate example of a successful Games, enabling the city to redefine and redevelop itself, with clear geographical outcomes. Hailed as "the most successful global model for post-industrial urban regeneration based on its urban design" (Degen, 2004, p. 131), the Olympics were used as a catalyst for physically and symbolically reconfiguring the city of Barcelona. Since then, sporting mega-events have been used by cities to improve infrastructure, regenerate run-down urban areas, promote economic growth and enhance placeimage. While it can be argued that this has been successfully achieved in Barcelona, however, other Olympic cities have fared less well.

In the early 1980s the urgency to regenerate Barcelona was economic, as the city found itself struggling with massive industrial closures and very high unemployment. As the city council argued, the major programmes necessary to stage the Olympics would have a vital social as well as economic purpose, namely to upgrade deprived districts and extend and improve public space and facilities (Marshall, 1996). The various infrastructural improvements vital to hosting a global sporting event were seen as having important social gains and contributing to long-term economic regeneration. Hence construction for the Olympics started a process of radically reordering and reassembling Barcelona's geography, and spatially transforming the city (Garcia and Degen, 2006).

The Barcelona example demonstrates the inherent local/global nexus central to the hosting of the Olympic Games. Barcelona used the Games - its global dimensions, platform and players - to embark on a peculiarly local programme of redevelopment and urban enhancement, aimed at improving the lives of its residents. As Degen (2004, p. 134) puts it, "cities rework and situate globalisation", with the Olympic Games providing a springboard for Barcelona to become a member of the 'global city' circuit. However, reminders of Barcelona's industrial past remain on the landscape (see fig 1), and in amongst the Olympic Village. Here it is useful to view the urban landscape as a palimpsest. Historically, a palimpsest referred to a writing tablet that could be used and reused. However, the tablet could never be entirely made clean and hence traces of former writings would build up. In the same way, urban 
landscapes are never completely erased of their prior uses and meanings (Crang, 1998). These marks on the landscape serve as important reminders of what the city was once like and, crucially, just how far it has come and how much change has taken place.

While the 1992 Games 'refashioned Barcelona as a tourist paradise' and is considered a 'good' games, the hosting of the 2004 Games in Athens has fared less well (Guardian, July 10 2005). Athens, pre-Olympics, found itself in a similar economic and social position to Barcelona. Similarly, the Athens Games were used to regenerate particularly deprived areas of the city by locating facilities in them. However, according to Howden (2005), there is little evidence that they have had any significant impact upon the city's urban problems. Indeed, the Athens Games have been widely reported to have left a scar on the city. Costing over $£ 8$ billion to stage, much of the sporting infrastructure (only 8 out of 21 Olympic facilities are being used) has stood empty since the closing ceremony with the nickname 'the herd of white elephants' unsympathetically attributed to the empty stadia and other venues.

In London, the 2012 Olympics are being used to regenerate an area east of the city centred on Stratford and the Lower Lea Valley. The Games' organisers have been very explicit about the need for regeneration, and regeneration objectives formed a central plank of London's bid. However, for the bid to succeed, this area of East London had to be constructed as in need and want of transformation through the hosting of the Olympics. According to the London Organising Committee of the Olympic Games' website, the main Olympic site is in dire need of regeneration with the Olympics able to unlock the potential that has so far gone untapped:

"The area in and around the Olympic Park is a site of huge potential. It has a young, diverse community but is also home to significant areas of deprivation. Much of the site itself is contaminated, derelict and abandoned. The waterways in the area have suffered from years of neglect: water quality is poor, river walls are in a bad condition and the landscape is scarred with abandoned shopping trolleys and other rubbish strewn along the river channels". (http://www.london-2012.co.uk/Urban-regeneration/ accessed $5 / 10 / 07)$ 
Without doubt, the area has been suffering from various environmental and social problems and has, in contrast to other areas of London, 'lost out' in terms of economic growth and development. However, this example demonstrates that "urban problems do not present themselves to policy-makers; rather they are defined in various ways" (Hall, 2006, p. 60). 'Problems' and a 'problem area' need to be identified and defined to legitimise regeneration interventions.

The Lower Lea Valley area will now be transformed into the Olympic Park which will hold the Olympic Village, housing athletes and the main venues including the Olympic Stadium, Velodrome, and BMX Circuit, plus the Fencing, Hockey, Handball and Basketball arenas, all of which will be accessible by the new Olympic Park Loop Road. After the Games, the Park will be transformed into "the largest urban park created in Europe for more than 150 years", with over 9,000 new homes, many aimed at key workers (such as nurses and teachers), and shops, restaurants and cafes for the local community. It is hoped the Games will spearhead long-term economic renewal; it is anticipated that thousands of new jobs will be created in the Park alone, many of them from the conversion of the International Broadcast Centre/Main Press Centre (see: http://www.london2012.com/plans/). A range of transport improvements serving the Park are already underway, including an extension to the Docklands Light Railway, increased capacity on the Jubilee Line and the upgrade of Stratford Regional Station. Hence, this extensive construction will see the area's geography considerably reworked. This change is aimed at giving the area an entirely new image. However, the change is not welcomed by and does not welcome everyone (as discussed below).

Through the example of the Olympics, we see how a global event has very local consequences on space and place. A city's spatial transformation involves a complex network of global and local forces reshaping the city's environment. In the same way as global mega-sporting events, stadium construction in many cities is the result of more than a desire to improve sporting facilities for both participants and spectators. North American cities have a tradition of competing strongly with each other for inward investment and the sports industry, especially the big football and baseball leagues, is particularly big business (Thornley, 2002). As a consequence, local states are intricately involved in the development of stadia as a means of attracting big players and businesses to their region. For example, the Dodger Stadium in Los 
Angeles was used to draw attention to the city's transition from a regional centre to a national metropolis (Lipsitz, 1984). Furthermore, the construction of the Superdrome in New Orleans and the Skydrome in Toronto set the stage for tourist-based growth in the cities' downtown areas (Bale, 2003), generating economic growth in their localities through their national and global reach. Stadia can become tourist attractions in their own right - notable for their design, for example, the Munich Olympic Stadium, or for the reputation of their team such as the Nou Camp Stadium in Barcelona. However, whilst there is an extensive literature on the role and impact of sports stadia in the development process in North America, corresponding awareness and interest in the UK has only emerged over the past decade. Here we draw on examples where stadia are used as stand alone developments or as part of a wider scheme of sporting activity.

Wembley stadium in West London is one example where sports development is being closely tied to wider regeneration objectives. Wembley is the UK's national stadium, and has recently gone through demolition and rebuilding. This extensive process, pushed forward by Wembley National Stadium Limited, Brent Council and Quintain Estates and Development plc, has been worked through a discourse of "prosperity for all', with especial emphasis placed on the benefits to the local area and the role of local residents. This is in contrast to other stadium developments which are often criticised for not involving local communities. For example, the construction of Vancouver's BC Place Stadium neglected existing residents and even led to the displacement of some 'locals' (Lee, 2002). To counter such concerns, the Wembley consortium webpage suggests:

"The benefits of having the national stadium at Wembley are far reaching for Wembley, Brent and indeed the Capital as a whole. The Stadium is being used to stimulate the regeneration of its surrounding area and Brent Council, as well as Wembley National Limited, are determined to maximise the positive impact of the new Wembley Stadium on the local area" (http://www.wembleystadium.com/brilliantfuture/localcommunity/regneration. $\underline{\mathrm{htm}}$ accessed 1/10/07)

In addition to the stadium itself, the development process is to include new homes, leisure facilities, shops, bars, restaurants, offices and public space. Thus, though undoubtedly a national building with global reach, the new Wembley intends to be 
positioned within a local arena of regeneration. The website promotes this inclusivity with a section dedicated to the needs and interests of the local community, making Wembley "a place where people are proud to live and eager to visit" (http://www.wembleystadium.com/about/localcommunity/introduction.htm accessed 1/10/07). However, Thornley (2002) notes that local people tend not to use stadia and the economic impacts of stadium construction on the immediate area are often limited. It then remains to be seen how successful the rebuilding of Wembley stadium is in delivering its promised wider benefits to the local community.

Another example of stadium development is the Millennium Stadium in Cardiff which came about in tandem with the Welsh Rugby Union's bid to host the 1999 Rugby World Cup, supported by Cardiff County Council. The city has viewed sport and related infrastructure as important drivers of growth and urban regeneration, and a 'good bet' in a post-industrial world (Jones, 2002). A new stadium on the site of the old was deemed necessary to host the event which, in the longer term, could provide conference and event facilities. It was constructed between 1996 and 1999 in the heart of Cardiff's commercial district. Unlike Wembley, the city centre location did not suffer from problems of deprivation and did not require regenerating, though it inevitably saw changes to its physical landscape. In addition to the "physically dominating stadium' (Jones, 2001a), infrastructural improvements included the development of the bus and train station, pedestrian improvements to the city centre and redevelopment of the river walk area.

Kidd (1995) suggests that benefits following stadium development may accrue unevenly across different sections of a city - often benefiting the already affluent. $\mathrm{He}$ also notes that stadia can act as a means of privatising urban public space and reasserting commercial control over a landscape formerly the preserve of minority or less well-of groups (see also Fainstein and Fainstein, 1986). The Millennium Stadium is a good example of how local areas can take on new meaning and lead to the disruption and destruction of previous amenities. The construction of the stadium led to the demolition of the Empire Road Pool, a participatory sporting facility available at low cost to local residents, which was replaced by relatively expensive retail and food outlets and a health club (Jones, 2001b). 
The process of completing the stadium on time has had repercussions on local residents in other ways too, most notably in the form of road closures, dust and construction noise. Another consequence of the hosting of the Rugby World Cup was the creation of a temporary 'red light district' in which prostitution would be tolerated for the duration of the event. This was intended to minimise the negative effects of prostitution incurring into residential areas (see Jones 2001a for further details) during such 'mega-events'. Hence the Millennium Stadium and the hosting of the Rugby World Cup were not uniformly positive in their impacts on the urban environment. To be effective, "[stadium] development needs to be integrated into a local regeneration strategy" (Thornley, 2002, p. 816) that considers the full range of effects on urban communities.

\section{Place meaning and sports development}

Besides the physical transformations stressed so far, sports development and its use as a tool of urban regeneration is also an effective and important means of changing place meaning and promoting place. In this section we shift focus to consider the role of sports developments in transforming and promoting certain kinds of images of place. For example, the Millennium Stadium development was used to promote newly devolved power in Wales - a "politically vibrant Wales, willing to take its place on the world stage" (Jones, 2002, p. 822). And Beijing is using the Olympics "to transform itself into a fitting capital for a $21^{\text {st }}$ century superpower" which, for the ruling Communist Party, "is also an important re-branding exercise" (http://news.bbc.co.uk/1/low/world/asia-pacific/6164330.stm accessed 4/10/07). As sports developments of varying size, scale and purpose transform the material geography of an area, so can they be used to transform the meanings of place. This section links to some of the issues discussed in Part Two of the book on the vision of sports development and draws on examples of the role of sports development in changing place meaning, and promoting an often very carefully controlled place image.

Since the mid-1980s, a central pillar of urban regeneration programmes has been the deliberate manipulation and promotion of place images (Hall, 2006). It is now the rule, rather than the exception, to find an urban area engaged in vigorous place promotion. In the US, place promotion or place marketing has become a multi-billion 
dollar industry as public relations experts rebrand, package, advertise and sell cities (Holcomb, 1993). Understandably, this process of place promotion has been used most rigorously and persuasively in areas affected by deindustrialisation and deprivation. Place promotion can work in two ways. First, it can operate within, to promote a certain image to its residents. For example, in Barcelona, it has been argued that the Olympics contributed to a "collective imaginary of democratic Barcelona for its citizens" (Balibrea, 2001, p. 199). Second, it can have an external function, promoting outwards to potential visitors and investors, and creating a tourist location. As Jones (2001a, p. 241) remarks, this is increasingly apparent:

"many cities that, hitherto, have not possessed a defined and globally acknowledged tourism product have attempted to take a 'short cut;' towards global recognition through the production of events which garner a global audience".

Thus place promotion works through an economic logic - of luring inward investment from industry, tourists and shoppers, and a social logic - of convincing local people that they are "important cogs in a successful community" (Philo and Kearns, 1993, p. $3)$.

'Geography of spectacle' is a term attached to heavily imagineered and marketed events, including the Olympic Games and other sporting occasions which are often global in reach (Ley, 2000). They are linked closely to the attendant national and global television audience that is seen as significant to the long-term fortunes of any city and, despite a universal language of promotion and marketing, extol the supposedly 'unique' qualities of 'unique' places (Philo and Kearns, 1993). According to Gratton et al (2006), in order to maximize place marketing, event organisers should work closely with broadcasters and other media to ensure the effective showcasing of key local attractions as the back drop to event coverage.

Turning attention to Barcelona again, the "seductive Barcelona of the 1990s" (Balibrea, 2001, p. 188) was primarily based on a particular hegemonic construction of the city through image:

"Along with the creation of the new Barcelona in bricks and mortar came a sponsored city promotion of Barcelona-as-concept, a seductive cocktail of 
architecture, imagination, tradition, style, nightlife and primary colours" (Timeout, 2002, p. 25).

The new and regenerated buildings, infrastructure and open spaces were imbued with symbolic meaning that emphasised culture and independence and represented the stark transformation from a run-down industrial metropolis to one of Europe's most desirable tourist venues (Degen, 2004).

Besides Barcelona as a tourist destination, Olympic and related developments were directed at changing the image of the city for its residents. Borne out of the city's history and politics, the Barcelona Games were effective in generating a strong sense of local patriotism, a sense of involvement and ownership:

"The Olympic Games generated a civil fraternity, materially embodied and reinforced in every architectural and urban project, which was perceived as required by the event" (Balibrea, 2001, p. 198).

This collective imaginary of the city and its Olympics is probably best exemplified in the way the city's inhabitants volunteered to participate in the Games' infrastructure. Very much as Philo and Kearns (1993) have suggested, this indicates that locals are vital components in a flourishing city. However, as Garcia and Degen (2006, p. 30) warn, as time has passed, this creation of a very place-specific identity has been criticised for being merely a "marketing exercise for the outside market", potentially leaving residents behind and feeling excluded (discussed further below).

Whilst Barcelona has focussed on the uniqueness of its geography and place identity, in contrast, the marketing for the 2012 Olympics in London appears to be 'placeless' and has been criticised for abolishing its geography (Jack, 2007). When London hosted the Olympics in 1948, the advertising combined the Olympic rings, Big Ben and an ancient statue of a Greek discus thrower; a clear and strong marker of both place and sporting endeavour. However, the 2012 logo, revealed in June 2007, has met with a furore from both the popular media and 'Londoners'. For many, criticism stems from the sidelining of the city in favour of a 'placeless' presentation of a sporting event. But, organisers have argued that they are purposely playing to a global field, and that the Olympics is not about one city. As the BBC explained:

"The objective in resisting an iconic image was to emphasise that while the Games is hosted in London, it is not just for London, but also for the UK and 
for the world" (http://news.bbc.co.uk/1/hi/magazine/6719805.stm accessed $4 / 10 / 07)$

However, the backlash has continued with Wolff Olins, the agency responsible for the 2012 logo, accused of being the "enemy of the local" and "eroding our already diminished sense of belonging" (Jack, 2007). Clearly, place promotion through sports development does matter, especially developments that are global in reach.

\section{Sports development, belongings and exclusions}

In the post-industrial city, spaces of sports development and consumption hold important symbolic value: "of the supposed unity of a class-divided and racially segregated city. Professional sports activities and events like the Los Angeles Olympic Games perform a similar [unifying] function in an otherwise fragmented society" (Harvey, 1989, p. 271). Hence, as stipulated above, sports developments often herald a sense of 'local patriotism' and a collective desire to rise to the occasion (Balibrea, 2001). However, as highlighted in the case study of Barcelona, this notion of coming together and inclusion often masks a reality of exclusions and segregation, with sporting developments including, benefiting, and being used by, specific social groups.

At this juncture the concepts of 'sense of place' and 'socio-spatial exclusion' are insightful. Sense of place refers to how people feel and think about places and is used by many geographers to emphasize that places are significant because they are the focus of personal feelings (Rose, 1995), as highlighted through discussions of the London 2012 logo. Sense of place is important because it is linked closely to identity and how we make sense of ourselves and our lives. Social exclusion, a term that has increasingly been adopted by politicians, refers to a "situation in which certain members of society are, or become, separated from much that comprises the normal 'round' of living and working within that society" (Philo, 2000, p. 751). While it is often conceptualised in strictly social terms, it has a clear spatial dimension and hence more accurately should be termed socio-spatial exclusion:

"excluded individuals will tend to slip outside, or even become unwelcome visitors within, those spaces which come to be regarded as the 'loci' of mainstream social life" (Philo, 2000, p. 751). 
Here, we look at exclusions and belongings in relation to sports development processes, venues, wider geographies, and concomitant image.

Writing about the BC Place Stadium project in Vancouver, Lee (2002) notes that despite being well received by the business community, the Provincial Government failed to take into consideration opposing views to the development. In particular, local residents' associations argued against the government engaging in stadium financing as, they felt, money could be better spent on affordable housing and other amenities. A central concern for many locals was that the development would result in increased house prices, which in turn would have an exclusionary impact on them. This is a fear that materialised in post-Olympics Barcelona (Marshall, 1996) and is echoed by local residents in East London in anticipation of the effects of the London Olympics:

"After the Olympics the property mob will move in. You'll get a lot of people with money here and it will never be the same again. I want to keep it like this". (Cited in The Guardian 21/06/06)

Hence local residents can be wary that sporting developments - of various size - can change the meaning of place, have an exclusionary impact on them in terms of being marginalized and not having their voices heard in the planning process, and then, very often, being the group least likely to be advantaged by any subsequent economic prosperity.

Preparation for the London Olympics in 2012 has seen the possession of a huge site in Stratford with the 'necessary' relocation of 208 businesses, 425 residents, 35 traveller families and 64 allotment holders (The Guardian 24/07/07). This process of relocation or eviction has been met with vocal and visible resistance within the local community (see figure 2). According to the political commentator, George Monbiot (2007), since the 1988 Olympics in Seoul, more than 2 million people worldwide have been driven from their homes to make way for the Olympics. One group that has been evicted from the London 2012 site are the Travellers from Clays Lane in Newham (see also Barkham, 2007). This follows the purging of similar groups for the Sydney and Barcelona Games. In an open letter to The Guardian newspaper (29/09/07), Tracie Giles, on behalf of the travellers, described the delays in their relocation and expressed her belief that they are considered 'easy prey' given that they do not live in 
'bricks and mortar'. Such examples show that exclusion can involve a process of physical removal and the creation of spatial boundaries whereby incursion into sites of sports development are prohibited. At the time of writing, this is evidenced by an 11-mile blue fence that marks off the 2012 Olympic site - leading commentators to ponder whether this is a necessary security measure or more a symbol of the Games' divisiveness (Beckett, 2007)

A sense of belonging or exclusion is, to a large extent, based on place-image. As remarked on above, the Barcelona Olympics effectively galvanised its local population to feel a part of the Games and take pride in their city. Image is thus not only about signification and symbolisation but can have very real material consequences for certain groups. Though Barcelona was considered to have achieved an inclusive Games, certain parts of the city, most notably the Ramblas and waterfront were 'morally cleansed' of their 'less desirable' users. Similarly, Manchester's city centre was 'cleansed' of prostitution during the 2002 Commonwealth Games (Degen, 2001 and 2004). This process represents a purification of space with deviant behaviours and bodies excluded from the polished image of place and its material spaces.

There are mounting concerns in Barcelona that the creation of the city as a globally recognised brand, precipitated by the Olympic Games, has become more interested in the tourist's and the world's gaze, rather than the lives of its own residents, and that economic concerns are beginning to overpower local needs (Degen, 2004). Tensions have developed over who has access to the city and whom the city is for, with locals beginning to voice concerns about the negative effects the increasing number of visitors has on their daily lives. And in 2005 a debate emerged in the local press over whether the city should restrict incoming tourists (Garcia and Degen, 2006).

The actual sites of sporting activity can also exclude. In his appraisal of the impacts of the Millennium Stadium in Cardiff, Jones (2001a) found that while the local population welcomed the stadium, attendance costs placed it out of the reach of many. Exclusion can further operate through hegemonic constructions of sporting spectators and participants, along the lines of class, race, gender and sexuality. At the start of the millennium in the UK, only $40 \%$ of members of ethnic minority groups participated in 
sport compared with $46 \%$ of the general population. Moreover, only $19 \%$ of Bangladeshi women took part in sport (Sport England, 2001). As Vertinsky (2004, p. 9) argues, it is necessary to explore the power relations which work to include and exclude:

"Different sporting places can be distinguished from each other through the operation of the relations of power that construct boundaries around them, creating spaces with certain meanings in which some relationships are facilitated, other discouraged".

In relation to sexuality, through research into women's footballing subculture in England, Caudwell (2007) has explored how lesbian-identified sports teams provide a challenge to the heterosexing of sport by resisting heteronormative meanings of sport space and sporting identities. Focusing on spectators, Muller (2007) has probed how heternormativity is naturalised within arena spaces of basketball in the USA, suggesting that teams and marketing personnel distance themselves from their lesbian fan-base and consumers. Instead, Muller argues, they prefer to reproduce a 'safe' heteronormative space and image, creating a sense of not belonging and being 'out of place' among a large cohort of their fan base.

At a broader level, Sport England is working to tackle social exclusion through promoting access to sport and encouraging more people of all ages, abilities and backgrounds to participate. Part of this process is ensuring there are enough suitable sporting venues - whether pools, halls, courts or pitches - to enable local sporting participation (Sport England, 2001). Hence sporting development is as much about the micro-geographies of these smaller venues and participation as national stadia and mega-events. One scheme, Sport Action Zones (SAZ), is based in some of England's most deprived communities and is aimed at increasing participation in sport and physical activity among hard-to-reach groups. In the SAZ in Liverpool, for example, recent research has showed the effectiveness of this scheme: overall regular participation in sport and physical activity went up by $5 \%$ from $60 \%$ to $65 \%$, and notably, among the most socio-economically deprived groups it increased by $10 \%$ from $43 \%$ to $53 \%$ (Sport England, 2006). Hence sports developments can have a positive impact in including people in sporting activity in and through their local area. 


\section{Conclusion}

By taking a geographical perspective, and working through various substantive issues and empirical case studies, this chapter has highlighted a number of issues of interest and concern to the management of sports development. First and foremost there is a need to balance the "global pressures and local effects" (Thornley, 2002, p. 818). Sports development is likely to be increasingly used as a tool of regeneration, as cities compete for prominence and investment on a global stage. By attracting inward investment, it is expected that exclusion and deprivation may be combated, although this is not a guaranteed outcome. There are expectations concerning the short-term impacts as well as the longer-term legacy, although not all outcomes can be foreseen. There are differential effects on different groups and at different scales: a balance is needed, for instance, between the needs of local residents and those of a tourist population, although where this balance lies is a subjective judgement.

The spatial impacts of sports developments are both material and symbolic. Development works best when all groups among the local population, including those generally excluded, are included through the planning and building process, and when they can themselves benefit, materially or otherwise, from the final sporting venue. Sports development can also be used in remaking place images, but is not allpowerful in its capacity to do so. The meanings of space and place are not fixed but dynamic and open to resistance and contestation. Thus successful sports development needs to construct place images that are inclusive. When successfully implemented, sports developments can evoke both national and local pride, and, as a consequence, criticism of sport-based development policy is sometimes labelled as unambitious or disloyal (Schimmel, 1995). Jones makes the salient point that in such an atmosphere, "a full understanding of the ways in which the [development]...impacts upon the host economy, and the extent of those impacts, can be compromised" (Jones, 2002, p. 821). Furthermore, images and attitudes may change over time, particularly if a development is perceived to be transformed from a public to a private space, and those who once saw themselves as part of the project cease to feel any ownership or belonging. Thornley $(2002$, p. 814) notes that "there is often popular support for a stadium if it is part of an Olympic or similar bid where national or city pride plays a part. However when transferred to a private club people's reaction often change to one of opposition". 
This chapter has stressed the importance of thinking about sports development not only in temporal terms but also in terms of the spatial, by highlighting the central and dynamic role of space. Space and place are not simply inert blank canvases to be built upon and developed, but are instead made and remade through the development process. As an encounter between people and place, sports developments can interrupt and dislodge prevailing, and engender and promote new, meanings of place.

From this, there are a number of clear lessons for sports development managers to heed:

1. The sports development process must be inclusive and managers must consult widely within the local community:

a. Managers need to include all local businesses and local social groups even the most disadvantaged and hard-to-reach - early on in the planning process

b. In depth and wide reaching community consultations could effectively mitigate frictions and conflicting interests within the local area

2. Sports development managers must be sensitive to the impact development has on the physical environment and use of space, and in changing place meaning:

a. Managers must consider not only potential tourism and inward investment but whether local residents benefit from the changes to their area

b. Any community consultation should gauge people's perceptions of the local area - its meaning and importance - to fully realise the impact of development

3. The short and long-term legacy of development and its impact on place and population need to be fully explored and, where possible, worked into a broader programme of regeneration that has material benefits for existing communities. 


\section{Case study:}

\section{The Barcelona Olympics: reconfiguring urban geography}

“The 1992 Olympic Games catapulted Barcelona onto a global stage and into the heart of the world's urban tourism network. In less than 5 years the city had been transformed from a run-down industrial metropolis into one of Europe's most desirable tourist venues". (Degen, 2004, p. 131)

In 1986 Barcelona was selected as the host city for the 1992 Olympic Games. The Barcelona Games became emblematic of how sports development has been used to successfully achieve postindustrial urban regeneration. This success has been considered a model in itself that has been extensively analysed, marketed and pursued by cities across the globe. Barcelona has thus become synonymous with linking successful sports development and urban regeneration.

The Barcelona Games grew out of a distinctly democratic process (Degen, 2004). Under General Franco's fascist regime, Barcelona had suffered from a lack investment - a consequence of the city's republican and anarchist involvements during the country's Civil War. After Franco's death in 1975, Barcelona found itself densely populated and characterised by a neglected city centre, old and degraded housing, chaotic planning policies, a lack of public facilities and open spaces. To counter these problems, the Socialist city council, elected in 1978, consciously pursued a programme of urban development to reverse the city's seeming decline. This was design-driven with the intention of reconstructing the city's geography and crafting an urban aesthetic that could express the new freedom, and previously marginalised Catalan identity and style.

A decisive moment in this process of urban development was the decision to bid to host the 1992 Olympic Games; an event that would provide the opportunity to make social and structural improvements and change the world's perception of the city. The then Mayor, Pasqual Maragall, openly acknowledged that the Games were being used as a pretext to obtaining three objectives: improving quality of life in the city, exploiting the economic impetus generated by the Games, and establishing Barcelona as a major European city (Barke and Tower, 1996). Thus, development within the city 
extended beyond the immediate construction of sporting and related venues to the necessary building of new ring roads, a drainage system, telecommunications infrastructure, and residential districts, and the transformation of the old port area - all of which were largely financed by the public sector (see Marshall, 1996 for details). The Olympic process thus created "a dynamic of seeing the city as a whole" (Garcia and Degen, 2006, p. 12), was presented as a 'one city' exercise in that it offered something to everyone, and was an effective means of uniting a city around a public project (Marshall, 1996).

At least initially, this development was conducted in a democratic and inclusive manner, generating a sense of ownership and civic pride among local residents who, for several years, had to tolerate considerable building work and inconvenience. Decisions relating to Olympic development were taken in a 'multi-level government frame' comprised mainly of the city council, the national and regional governments and the ad hoc offices created to implement the project, including the Olympic Committee Planning Office (Garcia and Degen, 2006). Together, they oversaw Barcelona's new physical makeover; a makeover that was used to signify a transition to democratic modernity, with a physical landscape used to communicate a specific image and way of seeing. As Degen (2004, p. 131) notes, the new Barcelona had an internal and external goal, aimed at local residents and potential tourists and investors respectively:

"the Games not only beamed its metamorphosed urban landscape (which often featured as a background to the sporting events) into the world's gaze, but also re-asserted its Catalan pride and identity"

Local, regional and national renewal was promoted through the reworked geography of the city, promoting a very new and glistening image.

However, a close examination of how sport developments are used to encourage and engender urban regeneration can 'unhide' the tensions and exclusions that a carefully crafted city and sporting image can erase. Despite the central role of the city council, little room was given to neighbourhood associations to voice their opinions (Garcia and Claver, 2003). Moreover, as Marshall (1996) argues, as the years passed, the public companies formed to implement various building programmes adopted a more entrepreneurial outlook. The clearest example of this change is in the post-Games use 
of the Olympic Village. While Mayor Maragall had promised that a large proportion of the village would be used as social housing, this never materialised, as private interests dominated. Further, there were criticisms within the city that work to improve the city's outer districts had fallen behind or had been neglected due to the focus on the Olympic infrastructure and Olympic-related areas of the city (Marshall, 1996).

Barcelona's use of the Olympics to front regeneration and promote the city to a worldwide audience was just one phase of post-industrial urban renewal pursued by public and private interests within the city (detailed in Marshall, 1996 and Garcia and Degen, 2006). Since the close of the Games, greater use of public-private partnerships has been used to regenerate and market the city through a programme of cultural activities and boosting the service economy. However, in spite of continued regeneration, "finding the equilibrium between success in the global arena and solutions for local social problems is today, just as it was in 1992, the main challenge for the city" (Muñoz, 2006).

Although it was "unanimously agreed that a major winner of the Olympics was the city of Barcelona itself' (Degen, 2004, p. 131) and Barcelona '92 is often cited as an exemplary Games (Muñoz, 2006), for cities hoping to replicate its success, Marshall (1996, p. 162) cautions against a 'one model fits all' outlook with the following warning:

"The Olympics effort was set in a quite unique historical context, and hence any imitation by other cities would have to be extremely careful, and would be more likely to lead to wrong conclusions than useful recipes"

Sports development needs to be cognisant of the significance of place-specificity, which has a profound effect on the local and global outcomes of any initiative.

Case study questions:

1. What lessons can be taken from Barcelona in the planning of other 'mega-events'?

2. How has Barcelona effectively capitalised on the Olympic Games' developments?

3. In what ways has 'place' had an important bearing on the development process and outcomes in Barcelona? 
4. How has 'glocalisation' been played out through the staging and legacy of the Barcelona Games? 